Journal of Agricultural Sciences
(Tarim Bilimleri Dergisi)

\title{
Determination of Proper Turning Frequency to Increase for Hatching Results in Hatching Eggs With Abnormal Shape Index
}

\author{
Serdar KAMANLI ${ }^{*}$ (D), Hüseyin AYGÖREN ${ }^{\text {(D) }}$, İsmail TÜRKER ${ }^{c}$ i⿺

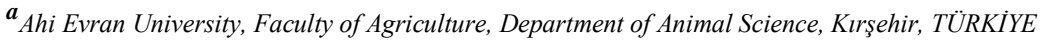

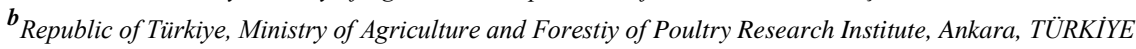

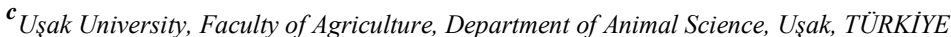

ARTICLE INFO

Research Article

Corresponding Author: Serdar KAMANLI, E-mail: serdarkamanli@hotmail.com

Received: 08 February 2021 / Revised: 10 April 2021 / Accepted: 11 April 2021 / Online: 25 March 2022

\section{ABSTRACT}

The aim of this study was to determine the optimum turning frequency for increasing the hatchability results in hatching eggs with abnormal shape index. For this purpose, 4050 hatching eggs obtained from 56 weeks old ATAK-S hybrid hens were used. Shape index was divided into 3 groups as 71 and smaller, $72-76,77$ and higher. The research was conducted according to a completely randomized factorial experimental design. The hatching eggs were incubated with turning frequency of 30 , 60 and 120 minutes. In the present study, fertility rate, hatchability, hatch of fertile, early, middle, late embryonic mortality, discard chick rate, chick quality, malformation and malposition rates were determined. The turning frequency was found to have a significant effect on hatch of fertile eggs and late embryonic mortality. It was found that turning frequency and shape index had no significant effect on the hatching results regarding discarded chicks, early embryonic mortality, malposition, malformation rate, and chick quality. Interaction between egg shape index and turning frequency did not influence hatching traits and chick quality. It was determined that there was no interaction effect between turning frequency and shape index on all the characteristics discussed. According to the results obtained from the research, it was observed that the 30 and 120 minute turning frequency of hatching eggs with different shape indexes had a negative effect on the hatchability of fertile eggs and late embryo mortality. It was concluded that even if the shape index of the hatching eggs were different, the optimum turning frequency should be every 60 minutes.

Keywords: Abnormal eggs, Hatching results, Shape index, Turning frequency

(C) Ankara University, Faculty of Agriculture

\section{Introduction}

Hatchery procedures is one of the important steps in poultry production, since nowadays hatching equipment of high-developed technology is available. Environmental factors such as temperature, humidity, ventilation and turning are automatically regulated, which provides more than 90\% hatching efficiency (Y1ldırım \& Yetisir 2004; Bruggeman et al. 2007; Elibol 2009; King'ori et al. 2011).

Despite a visible effort by breeding enterprises, it has been determined that it is impossible to produce eggs at a level that will meet the incubation needs. In studies conducted up to date, it has been reported that some egg parameters could lead to embryo death (Narushin \& Ramanov 2002; Durmuş 2014).

It has been reported that turning the eggs in the first $18^{\text {th }}$ day of incubation is essential for the proper development of the embryonic membranes and the proper positioning of the embryo (Eycleshymer 1907; New 1957; Robertson 1961a; Robertson 1961b; Lundy 1969; Deeming 1989). While some studies have reported optimum turning frequency as 96 times daily (Elibol \& Brake 2003; Wilson et al. 2003), turning 24 times a day was reported sufficient in commercial hatcheries due to similar results of 96 times a day (Freeman \& Vince 1974). It was stated that the impairment of the position in the embryo may be due to insufficient turning frequency, improper turning angle (Byerly \& Olsen 1931; Byerly \& Olsen 1933; Robertson 1961a; Landauer 1967; Lundy 1969; Wilson et al. 2003), the absence of turning in the first week of incubation and older flock age (Elibol \& Brake 2004).

Egg quality is an important factor that affects hatching results (Elibol 2009). Characteristics of the egg quality can be classified in two groups: internal and external quality. External quality characteristics are egg weight, shape index, and shell quality (Narushin \& Romanov 2002; Sarıca \& Erensayın 2009; Durmus 2014). Hatching eggs with a shape index of 72 - 76 have the optimum shape index value, while hatching eggs with shape index below and above these values have low hatchability and hatchability of fertile eggs, whereas late-stage embryo mortality and malposition rates are significantly increased (Asc1 \& 
Durmus 2015). Although the low angle of turning of the eggs during incubation increases the malposition rate, it has been reported that this rate can be reduced by increasing the number of turning of the eggs (Elibol \& Brake 2004).

As mentioned above, high rates of malposition have been reported to negatively affect hatching results. It has been predicted that the frequency of incubation may be the solution to this situation. In order to increase the hatching results of abnormal eggs, in this study, 30, 60 and 120 minutes of turning frequencies were applied to the eggs with low, high and normal shape indexes and the effects on hatching results have been determined.

\section{Material and Methods}

The research was implemented with 4050 hatching eggs obtained from 56 weeks old ATAK-S hybrid parents that were classified into shape index groups as described below with Rauch shape index measuring instrument.

1) Shape index 71 and smaller

2) Shape index $72-76$

3) Shape index 77 and above

Hatching eggs were stored for 7 days in a room at $15{ }^{\circ} \mathrm{C}$ and $80 \%$ relative humidity. The turning frequency on the incubator was set to 30, 60 or 120 minutes. The study was carried out in random blocks in $3 * 3$ factorial experimental designs with 3 replications. Incubation trays with a hatching capacity of 150 eggs were considered as replicate. Therefore $3 * 3 * 3 * 150=4050$ hatching eggs have been used. The eggs classified according to shape index were placed in trays and placed in Pas Reform brand 19.200 capacity smart type incubators, and pre-warmed in rooms with $24{ }^{\circ} \mathrm{C}$ and $75 \%$ relative humidity for 8 hours, then transferred to the incubator with a temperature of $37.8{ }^{\circ} \mathrm{C}$ and relative humidity of $50 \%$. After incubation for 18 days and being checked for fertility, eggs were transported to hatching machines providing $36.5-37{ }^{\circ} \mathrm{C}$ temperature and $55-78 \%$ relative humidity. Chicks were hatched from the eggs that had been kept there for 3 days. During the research, the following characteristics have been determined and calculated with the formula below. Fertility was determined by cracking the eggs separated by lamp control on the $18^{\text {th }}$ day of the incubation. Poor quality chicks that cannot be sold was described as discarded chick.

Fertility: (Number of fertile eggs / Number of eggs placed in incubator) * 100.

Hatchability: (Number of alive chicks hatched/ Number of eggs placed in incubator) $* 100$.

Hatch of fertile (Number of alive chicks hatched / number of fertile eggs) $* 100$.

Early embryonic mortality: (Number of embryos died between 0-6 days of incubation / Number of fertile eggs) * 100 .

Mid embryonic mortality: (Number of embryos died between 7-18 days of incubation / Number of fertile eggs) * 100 .

Late embryonic mortality: (Number of embryos died between 19-21 days of incubation / Number of fertile eggs) * 100 .

Discarded chicks: (Number of discarded chicks / Number of eggs placed in incubator) * 100 .

Chick quality: Pasgar score was used as chick quality determination method developed by Pas Reform (Boerjan 2006).

Malformation and Malposition: Eggs with death embryo in shell were examined and malformation and malposition rates were determined.

\subsection{Statistical analysis}

For all the examined parameters, normal distribution of the data was checked with the Kolmogorov-Simirnov test and the homogeneity of the group variances was assessed with the Levene test. General Linear Model (GLM) analysis was applied to evaluate the features that fulfill the assumptions, and Tukey multiple comparison tests at 5\% significance level was used to detect significant differences. Minitab 16 package statistics program was used to evaluate the data.

The applied mathematical model is provided below.

$\mathrm{Y}_{\mathrm{ijk}}=\mu+\mathrm{a}_{\mathrm{i}}+\mathrm{b}_{\mathrm{j}}+\mathrm{a} \mathrm{b}_{\mathrm{ij}}+\mathrm{e}_{\mathrm{ijk}}$

$\mathrm{Y}_{\mathrm{ijk}}$, The value of any of the research parameters; $\mu$,Population average; $\mathrm{a}_{\mathrm{i}}$, Effect of the turning frequency (30-60-120 minutes); $j$, Effect of the shape index $(\leq 71,72-76, \geq 77) ; a b_{i j}=$ Interaction between turning frequency (i) and shape index $(j)$; $\mathrm{e}_{\mathrm{ijk}}$, Experimental error

\section{Results and Discussion}

As indicated, results of the evaluation of the hatchability data are presented in Table 1. It was determined that the turning frequency, shape index and their interaction had an insignificant effect on hatchability $(\mathrm{P}>0.05)$. 
Table 1- Effects of egg shape index and turning frequency on hatchability

\begin{tabular}{lcccc}
\hline $\begin{array}{l}\text { Turning } \\
\text { Frequency }\end{array}$ & $\geq 77$ & Shape Index & Average \\
\hline 30 minutes & $68.44 \pm 2.62$ & $71.11 \pm 1.78$ & $71.33 \pm 7.33$ & $70.17 \pm 1.80$ \\
60 minutes & $73.56 \pm 1.82$ & $75.78 \pm 0.80$ & $74.33 \pm 2.33$ & $74.58 \pm 0.87$ \\
120 minutes & $69.56 \pm 1.60$ & $70.89 \pm 0.589$ & $75.62 \pm 0.39$ & $71.57 \pm 1.07$ \\
Average & $70.52 \pm 1.29$ & $72.59 \pm 0.99$ & $73.76 \pm 2.15$ & \\
\hline
\end{tabular}

Hatchability of fertile eggs data is shown in Table 2. It has been determined that the effect of turning frequency on this parameter was significant $(\mathrm{P}<0.05)$. The egg shape index value did not have a significant effect on the hatchability of fertile eggs and turning frequency $*$ shape index interaction was insignificant $(\mathrm{P}>0.05)$.

Table 2- Effects of egg shape index and turning frequency on hatchability of fertile eggs

\begin{tabular}{lcccc}
\hline & & Shape Index & Average \\
Turning & $\geq 77$ & $72-76$ & $\leq 71$ & \\
Frequency & $79.74 \pm 2.05$ & $84.65 \pm 1.45$ & $81.78 \pm 4.98$ & $82.09 \pm 1.49^{\mathrm{b}}$ \\
\hline 30 minutes & $86.44 \pm 0.84$ & $85.056 \pm 0.64$ & $87.44 \pm 2.40$ & $86.17 \pm 0.67^{\mathrm{a}}$ \\
60 minutes & $79.63 \pm 0.61$ & $80.20 \pm 1.76$ & $86.34 \pm 0.02$ & $81.52 \pm 1.22^{\mathrm{b}}$ \\
120 minutes & $81.94 \pm 1.31$ & $83.30 \pm 1.04$ & $85.19 \pm 1.80$ & \\
Average & & & & \\
\hline
\end{tabular}

${ }^{\text {ab }}$ Values within a column with different superscripts differ significantly at $\mathrm{P}<0.05$

The outcomes obtained as a result of the evaluation of the fertility data are presented in Table 3 . It was found that the effects of turning frequency, shape index and turning frequency*shape index interaction on the fertility rate were also insignificant $(\mathrm{P}>0.05)$.

Table 3- Effects of egg shape index and turning frequency on fertility

\begin{tabular}{lcccc}
\hline Turning & \multicolumn{3}{c}{ Shape Index } & Average \\
Frequency & $\geq 77$ & $72-76$ & $\leq 71$ & \\
\hline 30 minutes & $85.78 \pm 1.24$ & $84.00 \pm 1.39$ & $87.00 \pm 3.67$ & $85.42 \pm 1.03$ \\
60 minutes & $85.11 \pm 2.26$ & $89.11 \pm 1.46$ & $85.00 \pm 0.33$ & $86.58 \pm 1.15$ \\
120 minutes & $87.33 \pm 1.54$ & $88.44 \pm 1.24$ & $87.58 \pm 0.42$ & $87.81 \pm 0.68$ \\
Average & $86.07 \pm 0.93$ & $87.19 \pm 1.05$ & $86.53 \pm 1.08$ & \\
\hline
\end{tabular}

The findings of early embryo mortality rate are provided in Table 4. On the early embryo mortality rate, the turning frequency, shape index and turning frequency*shape index interaction were determined to be insignificant $(\mathrm{P}>0.05)$.

Table 4- Effects of egg shape index and turning frequency on early period embryo mortality rate

\begin{tabular}{lcccc}
\hline Turning & \multicolumn{3}{c}{ Shape Index } & Average \\
Frequency & $\geq 77$ & $72-76$ & $\leq 71$ & \\
\hline 30 minutes & $12.22 \pm 1.49$ & $6.08 \pm 1.29$ & $9.07 \pm 6.13$ & $9.13 \pm 1.66$ \\
60 minutes & $7.01 \pm 0.74$ & $7.48 \pm 1.31$ & $5.49 \pm 0.76$ & $6.81 \pm 059$ \\
120 minutes & $9.91 \pm 1.23$ & $8.75 \pm 1.66$ & $7.91 \pm 2.61$ & $8.97 \pm 0.89$ \\
Average & $9.71 \pm 0.96$ & $7.44 \pm 0.81$ & $7.49 \pm 1.86$ & \\
\hline
\end{tabular}

The findings of the mid-term embryo mortality rate are illustrated in Table 5. Turning frequency, shape index and turning frequency*shape index interaction were also found to be insignificant on medium-term embryo mortality rate $(\mathrm{P}>0.05)$. 
Table 5- Effects of egg shape index and turning frequency on mid-term period embryo mortality rate

\begin{tabular}{ccccc}
\hline Turning & & Shape Index & & Average \\
Frequency & $\geq 77$ & $72-76$ & $1.17 \pm 0.43$ & $1.86 \pm 0.37$ \\
\hline 30 minutes & $2.61 \pm 0.73$ & $1.58 \pm 0.45$ & $3.14 \pm 1.58$ & $2.50 \pm 0.46$ \\
60 minutes & $2.07 \pm 0.90$ & $2.50 \pm 0.28$ & $0.38 \pm 0.38$ & $1.70 \pm 0.40$ \\
120 minutes & $2.30 \pm 0.46$ & $1.99 \pm 0.64$ & $1.56 \pm 0.68$ & \\
Average & $2.33 \pm 0.37$ & $2.02 \pm 0.27$ & \\
\hline
\end{tabular}

Data related to the late embryo mortality rate are presented in Table 6. It has been determined that the effect of turning frequency on this feature was significant $(\mathrm{P}<0.05)$. It was determined that the egg shape index value did not have a significant effect on the late embryo mortality rate and the turning frequency*shape index interaction was insignificant $(\mathrm{P}>0.05)$.

Table 6- Effects of egg shape index and turning frequency on late period embryo mortality rate

\begin{tabular}{lcccc}
\hline & & Shape Index & & Average \\
Turning & $\geq 77$ & $72-76$ & $\leq 71$ & \\
Frequency & $5.43 \pm 0.72$ & $7.43 \pm 0.82$ & $6.81 \pm 2.01$ & $6.53 \pm 0.62^{\mathrm{b}}$ \\
\hline 30 minutes & $3.93 \pm 0.47$ & $4.47 \pm 0.80$ & $3.93 \pm 1.58$ & $4.13 \pm 0.44^{\mathrm{a}}$ \\
60 minutes & $7.65 \pm 1.19$ & $8.56 \pm 0.58$ & $4.99 \pm 1.83$ & $7.32 \pm 0.77^{\mathrm{b}}$ \\
120 minutes & $5.67 \pm 0.69$ & $6.82 \pm 0.71$ & $5.24 \pm 0.97$ & \\
Average & & & & \\
\hline
\end{tabular}

${ }^{\text {ab }}$ Values within a column with different superscripts differ significantly at $\mathrm{P}<0.05$

Data on discarded chicks (Table 7), malposition rate (Table 8), malformation rate (Table 9) and pasgar score chick quality values (Table 10) were not significantly affected by the turning frequency, shape index and turning frequency*shape index interaction $(\mathrm{P}>0.05)$.

Table 7- Effects of egg shape index and turning frequency on discarded chick rate

\begin{tabular}{lcccc}
\hline & & Shape Index & Average \\
Turning & $\geq 77$ & $72-76$ & $\leq 71$ & $0.33 \pm 0.18$ \\
Frequency & $0.00 \pm 0.00$ & $0.22 \pm 0.22$ & $1.00 \pm 0.33$ & $0.33 \pm 0.18$ \\
\hline 30 minutes & $0.44 \pm 0.44$ & $0.44 \pm 0.22$ & $0.00 \pm 0.00$ & $0.42 \pm 0.12$ \\
60 minutes & $0.44 \pm 0.22$ & $0.44 \pm 0.22$ & $0.33 \pm 0.33$ & $0.44 \pm 0.22$ \\
120 minutes & $0.30 \pm 0.16$ & $0.37 \pm 0.12$ & 0 \\
Average & &
\end{tabular}

Table 8- Effects of egg shape index and turning frequency on malposition rate

\begin{tabular}{lcccc}
\hline & & Shape Index & Average \\
Turning & $\geq 77$ & $72-76$ & $\leq 71$ & $3.03 \pm 0.23$ \\
Frequency & $2.59 \pm 0.24$ & $3.19 \pm 0.50$ & $3.44 \pm 0.24$ & $3.83 \pm 0.55$ \\
\hline 30 minutes & $2.60 \pm 0.65$ & $4.72 \pm 0.86$ & $4.32 \pm 1.19$ & $5.11 \pm 0.65$ \\
60 minutes & $5.12 \pm 1.15$ & $6.05 \pm 0.80$ & $3.70 \pm 160$ & \\
120 minutes & $3.44 \pm 0.57$ & $4.65 \pm 0.55$ & $3.82 \pm 0.54$ & \\
Average & & & & \\
\hline
\end{tabular}

Table 9- Effects of egg shape index and turning frequency on malformation rate

\begin{tabular}{lcccc}
\hline Turning & & Shape Index & & $\leq 1$ \\
Frequency & $\geq 77$ & $72-76$ & $0.40 \pm 0.40$ & $0.39 \pm 0.15$ \\
\hline 30 minutes & $0.51 \pm 0.26$ & $0.27 \pm 0.27$ & $0.00 \pm 0.00$ & $0.20 \pm 0.13$ \\
60 minutes & $0.53 \pm 0.27$ & $0.00 \pm 0.00$ & $0.38 \pm 0.38$ & $0.38 \pm 0.14$ \\
120 minutes & $0.50 \pm 0.25$ & $0.25 \pm 0.25$ & $0.26 \pm 0.16$ & \\
Average & $0.52 \pm 0.13$ & $0.17 \pm 0.12$ & & \\
\hline
\end{tabular}


Table 10- Effects of egg shape index and turning frequency on chick quality pasgar score values

\begin{tabular}{lcccc}
\hline & & Shape Index & & Average \\
Turning & $\geq 77$ & $72-76$ & $9.74 \pm 0.134$ & $9.77 \pm 0.028$ \\
\hline 30 minutes & $9.76 \pm 0.003$ & $9.81 \pm 0.017$ & $9.77 \pm 0.043$ & $9.78 \pm 0.021$ \\
60 minutes & $9.76 \pm 0.047$ & $9.80 \pm 0.026$ & $9.77 \pm 0.013$ & $9.74 \pm 0.036$ \\
120 minutes & $9.67 \pm 0.090$ & $90.79 \pm 0.020$ & $9.76 \pm 0.037$ & \\
Average & $9.73 \pm 0.032$ & $9.80 \pm 0.011$ & \\
\hline
\end{tabular}

Late embryo mortality rate was significantly lower at 60 minutes of turning frequency than the other frequencies. The hatchability of fertile eggs was significantly higher at the turning frequency of every 60 minutes compared to the other frequencies. In the case of the eggs with different shape indexes, it was observed that the turning done at an angle of $90^{\circ}$ degrees every 60 minutes gave better results. It is considered that the hatchability of fertile eggs is higher in this group than the other turning groups due to the lower rate of late embryo mortality. However, this situation does not appear to have a positive effect on hatchability. It is suggested that a positive effect will occur on hatchability by increasing the number of replicates. It has been observed that egg shape index and turning frequency have no effect on the other hatching features that are examined in the present study.

Freeman \& Vince (1974) stated that it is enough to turn eggs 24 times a day in commercial hatcheries. The results obtained in our research in terms of turning frequency support this finding. Baspinar et al. (1997) reported a positive correlation $(r=0.809)$ between embryonic mortality and shape index in their study where the incubation characteristics of Japanese quail eggs depend on the egg weight and shape index. However, there was no significant difference in embryo mortality rates in terms of shape index. They determined that the effect was insignificant. Esen \& Ozcelik (2002), Turkyılmaz et al. (2005), Y1lmaz \& Cağlayan (2008) and Sari et al. (2010) reported that the effect of shape index on incubation characteristics was insignificant in their studies in quails. It is observed that the results obtained for the shape index in the present study are in line with these findings. Asc1 \& Durmus (2015) reported that the egg shape index has a significant effect on the late embryo mortality rate, hatchability of fertile eggs, hatchability and malposition, and eggs with normal shape index have a better outcome than others. Durmus (2014), Narushin \& Ramanov (2002) reported that the hatchability of fertile eggs is much lower in the round shaped eggs than the pointed ones. However, while the effect of the shape index discussed on the hatching results was found to be insignificant, it was determined that the effect of the turning frequency on the hatchability of fertile eggs and late-stage embryo mortality rate was important. Considering these findings it is concluded that the outcomes of the study differ. Further work is essential to clearly define these discrepancies.

According to the results obtained from the present study, it was determined that the 30 and 120 minute turning frequency of hatching eggs with different shape indexes had a negative effect on the hatchability of fertile eggs and late embryo mortality. It was concluded that even if the shape index of the hatching eggs were different, the optimum turning frequency should be every 60 minutes.

\section{Acknowledgements}

We thanks to the Republic of Turkey Ministry of Agriculture and Forestry General Directorate of Agricultural Research and Policies for their support to the project.

\section{References}

Asc1 E \& Durmus I (2015). Effect of egg shape index on hatching characteristics. Agri-Food Science Technology 3: 583-587. Doi:10.24925/turjaf.v3i7.

Baspınar E, Y1liiz M A, Özkan M M \& Kavuncu O (1997). The effect of egg weight and shape index on hatchability in japanese quail eggs. Turkish Journal of Veterinary and Animal Science 21: 53-56

Boerjan M (2006). Chick vitality and uniformity. Retrieved in: 10 April 2021 International Hatchery Practice 20: 7-8. From http://www.positiveaction.info/pdfs/articles/hp20.8p7.pdf.

Bruggeman V, Tona K, Onagbesan O \& Decuypere E (2007). Hatching egg and chick quality. In: $29^{\text {th }}$ the Poultry Science Symposium Series 23-25 July, 2007, Edinburgh, UK, pp. 224-236

Byerly T C \& Olsen M W (1931). The influence of gravity and air-hunger on hatchability. Poultry Science 10: $281-287$. Doi:10.3382/ps.0100281.

Byerly T C \& Olsen M W (1933). Time and manner of determination of the malposition head in small end of egg. Poultry Science 12: 261265. doi:10.3382/ps.0120261.

Deeming D C (1989). Characteristics of unturned eggs: critical period, retarded embryonic growth, and poor albumen utilization. British Poultry Science 30: 239-249. Doi: 0.1080/00071668908417144.

Durmus I (2014). Effects of egg quality characteristics on hatching results. National Poultry Congress Proceedings Book, 9-11 October, Elazı $\breve{g}$, Turkey pp. 37 (In Turkish).

Elibol O \& Brake J (2003). Effect of frequency of turning from three to eleven days of incubation on hatchability of broiler hatching eggs. Poultry Science 3: 357-359. Doi: 10.1093/ps/82.3.357. 
Elibol O \& Brake J (2004). Identification of critical periods for turning broiler hatching eggs during incubation. British Poultry Science 45: 631-637. doi: 10.1080/00071660400006271.

Elibol O (2009). Embryo development and incubation. In: M Turkoglu \& Sarica M (Eds), Poultry Science Breeding, Nutrition and Diseases. $3^{\text {rd }}$ ed. Bey Ofset Publishing, Ankara. pp. 140-184. (In Turkish).

Esen A \& Ozcelik M (2002). The effect of age of parents, egg weight and shape index on hatchability in quails. Firat University Veterinary Journal of Healt Science 16: 19-25

Eycleshymer A C (1907). Some observations and experiments on the natural and artificial incubation of the egg of the common fowl. Biological Bulletin 12: 360-374. Doi: 10.2307/1535688.

Freeman B M \& Vince M A (1974). Incubation requirements. In: Development of the avian embryo. Retrieved in December, 10, 2019 from https://link.springer.com/book/10.1007\%2F978-94-009-5710-7.

King'ori A M (2011). Review of the factors that influence egg fertility and hatchability in poultry. International Journal of Poultry Science 10: 483-492. doi:10.3923/ijps.2011.483.492.

Landauer W (1967). The hatchability of chicken eggs as influenced by environment and heredity. Retrieved in December, 19, 2019 from https://www.opencommons.uconn.edu/saes/1.

Lundy H (1969). A review of the effects of temperature, humidity, turning and gaseous environment in the incubator on hatchability of hen's eggs. In: T C Carter \& B M Freeman (Ed), the fertility and hatchability of the hen's egg. Oliver \& Body, Edinburgh pp. 143-176

Narushin V G \& Romanov M N (2002). Egg physical characteristics and hatchability. World Poultry Science Journal 58: 297-303. Doi: $10.1079 /$ wps 20020023.

New D (1957). A critical period for the turning of hen's eggs. Journal of Embryology Experimental Morphology 5: 293-299

Robertson I S (1961a). The influence of turning on the hatchability of hens' eggs. The effect of rate of turning on hatchability. Journal of Agricultural Science 57: 49-56. Doi:10.1017/s0021859600050000.

Robertson I S (1961b). The influence of turning on the hatchability of hens' eggs. The effect of turning frequency on the pattern of mortality, the incidence of malpositions, malformations and dead embryos with no somatic abnormality. Journal of Agricultural Science 57: 57-69. Doi: $10.1017 / \mathrm{s} 0021859600050012$.

Sarı M, Tilki M, Saatci M, Isık S \& Onk K (2010). Effect of parental age, egg weight and shape index on hatchability traits and liveability in japanese quail (Coturnix coturnix japonica). Veterinary Journal of Health Science 24: 93-97

Sarıca M \& Erensayın C (2009). Poultry products. In: M Turkoglu, Sarica M (Eds), Poultry Science Breeding, Nutrition and Diseases. $3^{\text {rd }}$ ed. Bey Ofset Publishing, Ankara pp. 89-139. (In Turkish).

Turkyılmaz M K, Dereli E \& Sahin T (2005). Effect of shell thickness, shell porosity, shape index and egg weight loss on hacthability in japanase quail (Coturnix Coturnix Japonia). Journal of the Faculty of Veterinary Medicine, Kafkas University 11: 147-150

Wilson H R, Neuman S L, Eldred A R \& Mather F B (2003). Embryonic malpositions in broiler chickens and bobwhite quail. The Journal Applied Poultry Research 12: 14-23. doi:10.1093/japr/12.1.14.

Yildırım I \& Yetisir R (2004). Effects of different hatcher temperatures on hatching traits of broiler embryos during the last five days of incubation. South African Journal of Animal Science 34: 211-216

Yilmaz A \& Cağlayan T (2008). Egg weight, shape index, hatching weight and correlations among these traits in japanese quail (Coturnix coturnix japonica) with different colored plumages. Journal of the Faculty of Veterinary Medicine, Kafkas University 22: 5-8

(C) 2022 by the author(s). Published by Ankara University, Faculty of Agriculture, Ankara, Turkey. This is an Open Access article distributed under the terms and conditions of the Creative Commons Attribution (CC BY) license (http://creativecommons.org/licenses/by/4.0/), which permits unrestricted use, distribution, and reproduction in any medium, provided the original work is properly cited. 